\title{
IMPROVING SAFETY FOR DRIVERS AND FLEETS: HISTORICAL AND INNOVATIVE APPROACHES
}

\author{
Richard Grace \\ Robotics Institute \\ Carnegie Mellon University \\ Victor Suski \\ Engineering Department \\ American Trucking Associations
}

\begin{abstract}
Summary: A two-day conference that addressed "Improving Safety for Drivers and Fleets" was held at Carnegie Mellon University and sponsored by the 21st Century Driver and Truck Alliance and the Federal Motor Carrier Safety Administration (FMCSA). The conference brought together stakeholders within the trucking industry and safety experts from other industries to explore approaches to improve driver and fleet safety. The goal of the conference was to facilitate discussions among industry stakeholders as a first step in identifying and implementing effective safety processes that may advance the FMCSA's ambitious goal of 50\% reduction in truck-related fatalities by 2010. On Day One there were three sessions related to trucking and industrial safety. The first session offered two views of historical safety initiatives as a foundation for understanding current industry safety practices. The second session focused on current efforts by government, fleets and truck manufacturers. The third session provided an opportunity for presenters to describe successful safety programs not currently being widely applied to the trucking industry.
\end{abstract}

On Day Two a morning-long panel discussion considered the approaches presented the previous day. A subsequent brainstorming session involving all attendees generated other independent or related approaches. The goals of the discussions on Day Two were 1) to identify practical safety steps that can be applied by fleets and drivers now and in the near future and 2) to identify potential partnerships for implementing and testing new safety initiatives. Ultimately, the panelists and participants developed 26 action items that will be ranked and used as a springboard for future truck safety efforts.

\section{INTRODUCTION}

For two days, stakeholders within the trucking industry and safety experts from other industries met to explore fundamental issues and methods to improve truck driver and fleet safety. The goal of the conference was to facilitate discussions among these groups as a first step in identifying and implementing effective safety approaches to help meet FMCSA's ambitious goal of reducing truck related fatalities by $50 \%$ by 2010 . 
On Day One there were three sessions dedicated to trucking and industrial safety. The presentations in the first session provided a foundation for understanding traffic safety practices from two unique perspectives. The presentations in the second session focused on current safety efforts by government, fleets and truck manufacturers. The third session provided an opportunity for presenters to describe successful safety programs not currently being widely applied to the trucking industry.

On Day Two a morning-long panel discussion addressed the approaches presented on the previous day and resulted in a group brainstorming session to develop new or related approaches. The goal of the panel discussion and brainstorming session was to identify practical safety steps that can be applied by fleets and drivers now and in the near future. The participants in the brainstorming session generated a list of 26 action items. The $21^{\text {st }}$ Century Driver and Truck Alliance will use these action items as a baseline for continuing these important conversations among fleets, government and researchers.

\section{ESTABLISHING COMMON GROUND}

Dr. Leonard Evans, President of Science Serving Society, and Dr. Nicolas Ward, Director of the ITS Institute Human Factors Research Laboratory at the University of Minnesota, opened the conference on Day One by presenting their differing views of historical crash data. Dr. Evans' presentation "Major Factors Relating to Highway Safety” focused on four major factors pertaining to highway safety: 1) roadway and traffic engineering; 2) automotive engineering; 3) driver behavior and 4) driver performance. Dr. Ward's presentation "Human Factors and Stable Systems: Can Technology Deliver What it Promises” addressed Intelligent Transportation Systems (ITS) as potential aids to traffic safety but only when there are realistic expectations, a human-centered approach and an understanding of the risks and consequences.

While each presenter emphasized different points and perspectives throughout their presentations, they came to the same conclusion. Both identified the driver, and primarily driver behavior, as the key to improving traffic safety. This is an example of finding common ground among seemingly different ideas and that is the mission of the $21^{\text {st }}$ Century Driver and Truck Alliance.

\section{ONGOING EFFORTS}

There were other opportunities during the first day, and throughout the rest of the conference, for participants to express their ideas in a politically neutral and positive environment. Even those who have historically differed in their opinions or those who have not previously had an opportunity to express their ideas were able to find their voice and move toward common understandings and goals. Six speakers from government, truck manufacturers, fleets and research organizations presented information about ongoing safety programs within the trucking industry. Two of these presentations are highlighted below as examples of the quantitative results that can be achieved through the application of specific safety programs. 
1. Barton and Tardif reported the benefits of incentive programs introduced into two Canadian fleets. One fleet reported a reduction in driver turnover from $98 \%$ to $20 \%$ between 1998 and 2000. A second fleet reported a reduction from 80\% to 30\% between 199 and 2001. Significant improvements in safety were also seen. Reportable incidents dropped by 33\% over the course of the study. (For more information, refer to the conference proceedings.)

2. McFann presented the results of a regional training tour at North American Van lines that was undertaken in the spring of 1999. It was conducted at 14 company locations with 350 drivers and/or staff attending. Vehicular training consisted of the North American Driver Awareness Course and the option of taking a check ride with an instructor and driving a truck simulator. Of the 350 participants, 55 participated in both vehicular programs and drove the simulator. After driver training, preventable crashes dropped by $50 \%$. (For more information, refer to the conference proceedings.)

\section{NEW PERSPECTIVES}

Three speakers used the third session on Day One to present thoughts outside of the industry regarding new directions for future programs. One of the presenters, Jack Balsamo, spoke about “Turning Concepts Into Reality: Practical Issues in Implementing Behavior Based Safety”. He detailed a mature methodology for positive behavioral change. He identified three items that influence and control behavioral decision-making:

- Antecedents

- Behavior itself

- Consequences

Studies have shown that influencing antecedents holds the greatest promise for changing behavior. The mechanism for employing behavior-based performance improvement is four-fold. Balsamo then defined a four-step methodology based on this conclusion that lead to positive improvements:

- Identify critical behaviors

- Gather data

- Provide feedback

- Use data to remove barriers

This methodology has been used in a variety of industries to improve safety. (For more information, refer to the conference proceedings.) 


\section{EVERYONE HAD A VOICE}

The other presentations from Day One were equally compelling as the ones highlighted in this paper. Their titles are listed below and the abstracts, papers and slides are available in the conference proceedings.

Dr. Ron Knipling, Chief of the Research Division, FMCSA

"Changing Driver Behavior Through On-Board Safety Monitoring"

Bill Gouse, Executive Engineer, Technology Planning, Freightliner LLC

"Intelligent Vehicle Driver Assistance Systems"

Thomas R Tray, Marsh Transportation Group

"Risk Management: Managing Safety and Loss Control and Much More"

Ray Barton, President, Ray Barton Associates, Louis-Paul Tardif, President, L. P. Tardif and Associates

"Implementing Successful Incentive Programs Within Transport Fleets"

K. Don Tullos C.D.S., Sr. Corporate Safety Advisor, FedEx Express

"FedEx Express - Four Steps of Safety"
John H. McFann, Project Administrator, North American Van Lines, Inc.

"Back to Basics with High Technology"

Jack Balsamo, Principal Consultant, Behavioral Science Technology

"Turning Concepts Into Reality: Practical Issues In Implementing Behavior Based Safety"

Robert M. Braswell, Technical Director, TMC "Explorations Into Positive Reinforcement Technique Using IVI Technology forImproving Driver Behavior"

Victor Suski, Senior Automotive Engineer, American Trucking Associations, Inc. "Highway Safety and Reliable Systems: We Have Met the Enemy and He is Us"

\section{A FOCUSED COLLECTIVE EFFORT}

After a brief recap, a morning-long panel session based on information presented the previous day, provided an opportunity for continued discussions on Day Two. These discussions led to a group brainstorming session where participants generated a list of action items for industry implementation.

The panelists generally agreed on the following points during the panel discussion:

- Industry should view truck drivers more as pilots to encourage the mindset that truck drivers are fundamentally different in terms of skill requirements from personal use vehicle drivers.

- The "No Zone” program sponsored by the U.S. Department of Transportation is a good example of safety outreach programs. Carriers need to develop similar outreach programs.

- More should be done to attract young people to a career as a driver. Image and professionalism are two important elements. Programs should be launched to recruit young drivers from new population segments that historically have avoided the profession.

- Money is an important factor. The ability to pass costs along to a consumer base is an important consideration, going back to the general public's attitude toward transportation costs and risks. Money in our society establishes "worth” for better or worse and therefore impacts professional outlook. 
- Career satisfaction is an important factor for driver retention. Driver considerations are important. Companies should consider: 1) giving drivers phone calls home; 2) giving meal compensation above industry norm; 3) doing things to affect change in the driver lifestyle and 3) treating drivers as one would treat other employees on travel for business. These actions may help attract drivers to the profession.

- Companies should encourage drivers to go back to school for continuing education.

- Companies should consider mandated vacation time to help foster driver well being. Vacation can help reduce work stress thereby producing improved safety outcomes. (European communities, for example, have 30-days of mandated vacation time).

During the subsequent brainstorming session, panelists and attendees together developed 26 action items that have been loosely organized into five categories: program, research, outreach, cooperative action and political action. A sampling of the main action items from each category include:

Program:

Research:

Outreach:
Develop programs for management to encourage driver participation in developing safety programs.

Establish real-time feedback systems for drivers, define good behaviors, reward mechanisms.

Establish voluntary national standards for driver training, relying on incentives for implementation by industry.

Cooperative Action: Provide outreach to shippers and ultimate customers to help develop solutions to safety issues. Make presentations/booklets to reach these communities.

Political Action: $\quad$ Work together for elimination of 12 percent excise tax on safety-related equipment. (For a complete list of action items, contact the authors of this report.)

\section{CONCLUSIONS}

This conference is only the beginning of the effort to focus on the driver as the key for improving safety and productivity within the trucking industry. The $21^{\text {st }}$ Century Driver and Truck Alliance will continue to mediate discussions among stakeholders regarding these goals. The next step in the process of following up on the proposed action items has already begun. Action items have been and will continue to be refined and expanded through continuous interaction with trucking stakeholders. The proposed steps in this task are:

- Distribute the action items to the conference attendees for clarification. Additional action items can be added at this time.

- Distribute the final action items to the attendees for a ranked vote. Each attendee will be asked to select the five action items for which he/she has the most interest.

- The votes will be tabulated and redistributed to the attendees.

- Sponsors will be sought to organize working groups for the top ranked action items.

- Those who were unable to attend the conference but who are interested in being a part of this important work will also be invited to join the working groups. 
The $21^{\text {st }}$ Century Driver and Truck Alliance will work with industry stakeholders to evolve these workshops into industry lead programs that make a significant difference in trucking safety and productivity.

\section{ACKNOWLEDMENTS}

This conference was sponsored by the $21^{\text {st }}$ Century Driver and Truck Alliance with financial support from the Federal Motor Carrier Safety Administration and those who attended the conference. 